\title{
KONSEKUENSI EKONOMI DAN PROSES POLITIK DALAM PENYUSUNAN STANDAR AKUNTANSI
}

Oleh:

\author{
Helmy Adam*
}

\begin{abstract}
Accounting standard setting merely is not a simple process because its standard regulatory approach should accommodate the interest of related parties. This interest is related to economic consequence caused by implementation of accounting standard which will be a reason of the battle of political process or politicization of accounting standard. Hence, existing argue about the attempt of related parties is associated to utility maximization standard in order to get most benefit standard, although in many cases like in China reflected government interest to keep their political ideology.
\end{abstract}

Keyword: Statement of Financial Accounting Standards (SFAS), moral hazard

\section{PENDAHULUAN}

Perkembangan standar akuntansi telah melampaui umur yang panjang, terutama di Amerika Serikat yang merupakan negara penganut sistem ekonomi pasar bebas. Dekade 1970-an masyarakat Amerika cukup tertarik melalui instiusi-institusi dalam menyoroti aspek sosial, lingkungan dan konsekuensi ekonomi dan dikristalisasikan dalam opini publik dalam penyusunan standar akuntansi (Zeff, 1978).

Dinamika perkembangan standar akuntansi diibaratkan sebagai sebuah roda berjalan tanpa henti seiring dengan proses yang mendasarinya. Akuntansi sebenarnya terbentuk dari fenomena ekonomi dari perkembangan berbagai entitas ekonomi yang ada, sehingga pembentukan standar akuntansi bukanlah suatu proses yang berjalan serta-merta, namun sangat memperhatikan aspek konsekuensi ekonomi yang diakibatkannya. Oleh karenanya apabila proses penyusunan standar penuh dengan tekanan dari berbagai pihak 
yang berkepentingan, bukanlah suatu hal yang mengejutkan karena adanya aspek economic consequences (Scroeder \& Clark, 1995: 13). Konstituen yang mungkin terkena imbas atau berkepentingan dengan standar akuntansi akan melakukan usaha untuk membuat standar yang mungkin terbentuk bisa memaksimalkan kepentingan mereka (Watt, 1977). Inilah yang dinamakan sebagai proses politik, yang menurut Zeff (2002) diartikan sebagai pembelaan atau pertimbangan self-interested dari pembuat standar mengenai aspek yang mungkin diasosiasikan dalam istilah economic consequences.

Artikel ini akan membahas bagaimana konsekuensi ekonomi menjadi faktor penentu penyusunan standar, di samping internalisasi konsekuensi ekonomi melalui proses politik dalam penyusunan standar akuntansi. Tinjauan ini akan diperkuat dengan memasukkan selayang pandang mengenai proses politik dalam penyusunan standar di beberapa negara di dunia yaitu Inggris, Amerika, Jerman, Australia (sebagai negara liberal) dan Cina (sebagai negara sosialis).

\section{Peny usunan Sstandar Akuntansi \& Masuknya Argumen Konsekuensi Ekonomi}

Watt \& Zimmerman (1978) dalam Roslender (1992:131) mengungkapkan sampai dengan standar akuntansi memiliki efek potensial pada arus kas masa depan, badan penyusun standar akan dipenuhi lobi-lobi perusahaan. Meskipun argumen teori pasar efisien dipakai, namun kenyataanya pilihan kebijakan akuntansi bisa mempengaruhi nilai perusahaan (Scott, 1997:186). Zeff (1978) dalam tulisannya berjudul "The Rise of Economic Consequences" mengartikan konsekuensi ekonomi sebagai

"...the impact of accounting report on the decision making behavior of business, government, unions, investors and creditors. 
Pertimbangan efek tersebut menjadikan berbagai pihak yang berkepentingan berharap bahwa penyus un standar mempertimbangkan hal ini, meskipun dalam berbagai hal, aspek tersebut menjadi dilema karena konstituen yang terkait sangatlah banyak, apakah itu dari entitas bisnis, asosiasi ind ustri, atau pemerintah. Pihak ini (oleh Zeff dikategorikan sebagai pihak ketiga) merupakan pihak selalu mengintervensi proses standar yang disusun oleh dewan standar.

\section{Mengapa Standar Akuntansi Ada?}

Kebutuhan mengenai standar akuntansi sendiri sebenarnya terlihat sebagai suatu kontroversi, sebab beberapa peneliti berargumen bahwa dengan adanya mekanisme pasar seharusnya penyediaan informasi keuangan sudah akan menyesuaikan dengan kualitas yang ditentukan pasar (Mathews \& Perera, 1993:106). Namun kenyataanya mekanisme pasar ini dianggap gagal dalam mendukung suplai informasi yang dikehendaki pengguna dalam skala patut dan efisien, sehingga diperlukan standar yang mengatur muatan informasi pada laporan keuangan (Rahman et.al, 1989 dalam Mathews \& Perera, 1993:106). Beberapa hal yang menjadi sumber kegagalan pasar menurut Scott (1996:386) yaitu externalities dan free-riding. Meskipun dua poin ini tidak ada, penyebab lainnya adalah informasi asimetri yang bersumber dari moral hazard dan adverse selection.

Karena kegagalan pasar dalam menciptakan informasi yang sesuai dengan keinginan pengguna, maka diperlukan pendekatan regulatori atau dengan menggunakan standar akuntansi yang diregulasi (Belkaoui, 2000:98; Mathews \& Perera, 1993:110). Argumen lain diungkapkan oleh Watt (1977) bahwa ekonomi moderen adalah yang diregulasi, sehingga Undang-Undang Perusahaan di Inggris, Australia, dan juga SEC 
sebagai agen pemerintah mensyaratkan adanya muatan disclousure tertentu pada laporan keuangan.

\section{Proses Penyusunan Standar Akuntansi: Argumentasi Masuknya Konsekuensi Ekonomi}

Proses penyusunan standar di Amerika oleh FASB (disadur dari Belkaoui, 2000:94) sebagai berikut:

1. Masalah yang dilaporkan, diidentifikasi dan dimasukkan dalam agenda

2. Kelompok tugas terdiri dari kelompok dengan pengetahuan akuntansi yang memadai, dan dari komunitas usaha yang ditunjuk. Staf teknis FASB yang berkonsultasi dengan kelompok tersebut menyiapkan sebuah catatan diskusi (Discussion Memorandum/MD) dalam sebuah laporan. MD mengungkapkan persoalan utama dan alternatif-alternatif yang dipertimbangkan oleh dewan

3. MD dipersiapkan bagi publik agar dapat diuji pada periode paling tidak selama 60 hari

4. Dilakukan dengar pendapat (public hearing), dimana sudut pandang yang berisi keunggulan dan kelemahan dari alternatif yang ada, disampaikan kepada dewan

5. Atas dasar pendapat lisan maupun tulisanyang diterima, dewan menyajikan konsep (exposure draft/ED) tentang pernyataan standar akuntansi keuangan yang diajukan. Tidak seperti MD, ED mengedepankan posisi dewa sesungguhnya dalam masalah laporan keuangan

6. ED dipersiapkan bagi publik agar dapat diuji dalam periode paling tidak selama 30 hari

7. Dengar pendapat lainnya dilakukan, untuk mengumpulkan pandangan tentang keunggulan dan kelemahan posisi yang dikemukakan dalam ED oleh dewan 
8. Berdasarkan pendapat lisan maupun yang diterima, dewan selanjutnya dapat melakukan kemungkinan-kemungkinan berikut ini:

(a) mengadopsi standar yang diajukan sebagai Statement of Financial Accounting Standards (SFAS)

(b) Mengajukan revisi atas standar yang diajukan, terkait dengan prosedur yang seharusnya dilakukan

(c) Menangguhkan pengeluaran standar baru dan menyimpannya dalam agenda

(d) Tidak mengeluarkan standar dan menghapus isu tersebut dari agenda

Dari teknis di atas, maka jelaslah bahwa partisipasi publik akan selalu diikutsertakan, meskipun keputusan akhir standar tetap otoritas FASB. Partisipasi publik atau dengan kata lain pihak yang terkait merupakan jalan masuk dari pertimbangan konsekuensi ekonomi bahkan politisasi dari standar akuntansi. Hal ini tidak dapat dipungkiri, bahkan Financial Accounting Foundation (FAF) sendiri mengungkapkan sebagai berikut:

Proses penyusunan standar akuntansi bisa dideskripsikan sebagai demokrasi karena, sepertihalnya semua badan pembuatan peraturan, hak Dewan adalah membuat aturan pada akhirnya bergantung pada persetujuan atas aturan tersebut. Tetapi karena penyusunan standar memerlukan beberapa prespektif, adalah tidak tepat untuk menentukan standar hanya berbasis pada pandangan konstituen. Sama dengan proses legis latif, ini harus dibicarakan dan semuanya harus diperdengarkan. Tetapi penyusun standar diharapkan mewakili keseluruhan konstituen dan bukannya satu grup saja. Proses ini bisa digambarkan sebagai suatu politik karena disana ada usaha pembelajaran terkait dengan perolehan standar yang akan dipakai. 
Tetapi bukanlah politis dalam pengertian jika akomodasi adalah disyaratkan untuk memperoleh pernyataan yang diterbitkan (Mathews \& Perera, 1993:106)

Public hearing dan exposure draft merupakan jalan masuk self-interest atau group interest dalam memaksimalisasi kepentingan mereka; atau dengan konsep ekonomi sebagai maksimalisasi transfer kekayaan (Watt \& Zimmerman, 1986:222).

Seperti diungkapkan Zeff (1978) bahwa penerapan standar atau regulasi akuntansi memiliki efek ekonomi terhadap berbagai pihak. Berikut ini beberapa contoh historis yang bisa menjadi bukti bahwa konsekuensi ekonomi dalam penyusunan standar akuntansi yaitu:

1. Ketika AIA (sekarang AICPA) (tahun 1941) yang didukung oleh konggres, menerapkan akuntansi persediaan LIFO dalam laporan keuangan, menetapkan nilai pasar wajar (the fair market value) digunakan untuk mencatat pengeluaran deviden saham. (ARB 11 tentang Corporate Accounting for Ordinary Stock Devidends)

2. Ketika CAP (tahun 1948) menetapkan historical cost accounting untuk depresiasi, sementara beberapa perusahaan telah menggunakan replacement cost depreciation (ARB 33)

3. Ketika tiga cabang dari American Electric Power Company menuntut di pengadilan federal (tahun 1958), agar AICPA dan juga CAP tidak mengeluarkan surat yang menyatakan bahwa the Deffered Tax Credit account seharusnya diklasifikasikan sebagai kewajiban. (ARB 44 -Revised)

4. Ketika SEC (tahun 1965) meminta product line diclousure dalam laporan keuangan yang dipublikasikan oleh perusahaan (segmental reporting), sebagai hasil tekanan dari Sub-komisi Senat untuk Anti Trust dan Monopoli 
5. Ketika APB, SEC, dan the bank regulatory agency (tahun 1968-1971) menyepakati digunakannya GAAP untuk bank, setelah usaha perbankan mengajukan keberatan atas pencantuman bad-debt provisions and losses on the sales of securities dalam laba bersih bank komersial

Konsekuensi ekonomi juga terbukti cukup besar meskipun periode FASB masih tergolong pendek (Zeff, 1978) misalnya berkaitan dengan akuntansi untuk biaya R\&D, self insurance, catastrophe reserve, development stage company, foreign currency fluctuations, leasing, dan masih banyak lagi. Beberapa penelitian tentang konsekuesi ekonomi dari standar FASB misalnya :

1. Translasi mata uang asing dengan SFAS No. 8 yang kemudian diganti dengan SFAS No. 52 karena ketidaknyamanan manajemen menerapkan SFAS 8 dengan argumen ukuran kinerja keuntungan dan kerugian trans lasi yang dianggap tidak handal .

2. SFAS No. 19 tentang penggunaan metode succesfully efforts menggantikan full costing untuk perusahaan migas. Penerapan SFAS 19 dianggap merugikan perusahaan migas dalam skala kecil karena laba perusahaan akan cenderung kecil dan tidak smooth sehingga mereka mengajukan permohonan ke pemerintah dan SEC untuk menyampaikan keberatannya (Wibisana 1992).

Penelitian sebelum periode FASB misalnya oleh Chow (1983) mengenai dampak UU Pasar Modal 1933 \& 1934 terhadap kekayaan pemegang saham dan bondholders. Efek konsekuensi ekonomi memang ada, dengan bukti mengenai efek negatif UU 1933 pada kekayaan shareholders, namun positif untuk bondholders wealth meski sangat lemah. Beberapa penelitian mengenai economic consequences atas SFAS seperti dikutip dalam Scott (1996: 202-207) misalnya penelitian Collins \& Salatka untuk SFAS 8 \& 52 dengan model ERC, penelitian Lev untuk dampak SFAS 19 dengan model penelitian even. Di luar 
itu ada satu riset mengenai argumen konsekuensi ekonomi misalnya oleh Khurana dan Loudder (1994) tentang SFAS 106 “Employers' Accounting for Postretirement Benefits Other Than Pension" meskipun tidak memperkuat penolakan penerapan standar ini.

\section{Political Process dan Intervensi Berbagai Pihak}

Proses politik dalam standar akuntansi diidentifikasikan sebagai usaha untuk memasukkan self-interest dalam penyusunan standar akuntansi (Zeff, 2002) atau dalam upaya untuk memaksimalisasi transfer kekayaan (Watt, 1977). Proses politik dalam standard setting merupakan isu yang menarik apalagi hal ini ada kaitannya dengan konsekuensi ekonomi saat standar akuntansi itu disahkan dan dipraktekkan.

Proses politik ini kadang bisa dilakukan dalam skala constituents lobbying. Konstituen ini terbagi dalam berbagai pihak, misalnya untuk riset McLeay et.al. (2000) di Jerman membagi dalam 3 kategori yaitu kalangan industri, auditor, dan akademisi. Dengan menggunakan dasar economic consequences, pihak-pihak yang terkena dampak ekonomi atas praktek standar akuntansi disebut sebagai kostituen. Beberapa kostituen ini akan membentuk grup (kelompok) yang melakukan lobi-lobi ke dewan standar, atau bahkan melalui media pemerintah atau pengadilan untuk melakukan klaim atas penerapan regulasi akuntansi baru.

Permasalahan akuntansi merupakan masalah politik yang sensitif, karena (1)kebutuhan penerbitan standar itu sendiri merupakan suatu kontroversi, dan (2)akuntansi membagi kekayaan di antara kelompok yang berbeda (Mathews \& Perera, 1993:105). Apalagi teori mengenai public information yang memberikan nilai tersendiri bagi public choice, akan memberikan berbagai muatan pada pihak-pihak yang berkepentingan untuk 
mengintervensi dewan standar untuk memberikan kontribusi yang menguntungkan bagi kepentingannya.

Kalau dianalisis dari 3 hipotesis teori akuntansi positif (Watt \& Zimmerman, 1986), maka akan ada tiga pihak terkait yaitu pemegang saham (bonus plan hypotheses), kreditur (debt convenant), pemerintah (political cost). Ketiga pihak ini akan menjadi sasaran perilaku manajemen, sehingga mereka melakukan klaim untuk menjaga agar kepentingannya tetap aman. Beberapa intervensi (klaim) atas perlakuan akuntansi juga dilakukan melalui perusahaannya, terbukti dengan adanya klaim implisit stakeholders dalam memilih metode akuntansi (Bowen et.al, 1995). Riset Bowen et al. (1995) menunjukkan pentingnya pemahaman dewan standar atas motivasi manajemen yang bergantung pada klaim stakeholders. Apalagi sudah terbukti oleh berbagai riset klasik tentang dampak laporan akuntansi terhadap perubahan harga atau return saham sebagai proxy kelakuan investor (lihat Chow, 1983).

\section{Beberapa Contoh Proses Politik}

Proses penyusunan stand ar berusaha untuk mengakomodasi kepentingan konstituen dengan berbagai model proses politik. Luehlfing (1995) memberikan mekasnisme dengan keterkaitan berbagai pihak yaitu: Crisis, Public Outcry, Washington Response, Accounting Intervention and Probation. Krisis merupakan fenomena yang menjadikan teriakan publik, yang nantinya akan diakomodasi oleh regulatori atau legislatif. Washington (pemerintah) akan mengakomodasi berbagai ketidakpuasan tersebut dengan melakukan intervensi dalam penyusunan standar akuntansi.

Ditinjau dari proses penyusunan standar dalam FASB sudah bisa dipastikan bahawa proses politik telah terjadi. Apabila exposure draft sudah dikeluarkan dan 
dilakukan public hearing, proses standar berarti sudah berusaha mengakomodasi kepentingan berbagai pihak. Surat-surat dari pihak-pihak yang berkepentingan diterima oleh FASB, dan telaah exposure draft dilakukan oleh asosiasi profesi misalnya telaah oleh anggota AAA dengan adanya FASB Prospectus “Earning per Share”. Kalangan akademisi meski bukan pemakai langsung standar FASB, bisa melakukan pembahasan-pembahasan mengenai exposure draft yang mungkin dipublikasikan sehingga terbaca oleh publik, sehingga mampu menjadi dasar pertimbangan bagai pada pemakai standar yang langsung. Interaksi akademisi dengan dewan standar diulas oleh Beresford dan Johnson (1995), melalui keterkaitan langsung, melalui keanggotaan dalam staf, anggota dalam advisory council, comment letters, keanggotaan AAA dan interaksi riset.

Namun Wibisana (1992) sangat khawatir bahwa penyusunan standar akuntansi lebih cenderung untuk akomodatif terhadap berbagai pihak, apalagi yang mayoritas. Meskipun Chris Robinson dalam Scott (1996:373-374) mencoba menganalisis beberapa pendapat para ahli bahwa membuat standar yang bagus sangat mungkin, namun kepentingan ekonomi efek standar juga harus bisa ditata dengan benar.

\section{Konsekuensi Ekonomi \& Proses Politik: Hubungan Sebab Akibat?}

Hubungan sebab akibat didasarkan pada analisis runtut waktu, yaitu sebab mendahului akibatnya, artinya konsekuensi ekonomi yang menjadi dasar (sebab) terjadinya proses politik dalam standard setting. Jika dianalisis secara mendasar, proses politik merupakan usaha untuk melakukan lobi-lobi dalam memaksimalkan transfer kekayaan bagi pihak yang berkepentingan. Watt \& Zimmerman (1986: 222) mengindikasikan bahwa alasan ekonomi dalam proses politik merupakan usaha politisi untuk memaksimalkan utilitasnya. Jadi sesuai yang diungkapkan Wibisana (1992) bahwa 
masalah dampak ekonomi menjadikan proses standar menjadi problematik sehingga dengar pendapat dan lobi menjadi suatu proses yang diharuskan.

Masalahnya apakah proses politik itu selalu disebabkan oleh konsekuensi ekonomi yang menyertai standar akuntansi? Hal ini ternyata menjadikan proses standar itu bukan murni dari konsekuensi ekonomi semata, atau bahayanya standar yang disahkan bukan yang terbaik dari sudut pandang kualitas laporan keuangan, melainkan yang mampu mengakomodasi kepentingan terbesar, atau bahkan menjadi suatu permainan politik praktis (Wibisana, 1992).

Kenyataannya bahwa standar akuntansi tidaklah lepas dari intervensi pemerintah. Watt (1977) mengungkapkan bahwa teori akuntansi keuangan perusahaan harus bisa menjelaskan persyaratan pemerintah dan regulasi laporan keuangan. Fakta bahwa kebijakan penentuan tarif/insentif fiskal dan harga adalah berdasarkan accounting numbers (Zeff, 1978); menjadikan manajer korporasi melakukan lobi ke agen dewan pembuat standar untuk membuat standar yang berimplikasi pada tarif yang menguntungkan (Miller, 1994:7). Perilaku birokrat juga bisa mempengaruhi proses standar, apalagi berkaitan dengan regulasi krisis. Ujung-ujungnya juga ke masalah ekonomi, yaitu politisi dan birokrat menginginkan costly information dalam proses politik sehingga mampu memberi kesempatan baginya untuk mengendalikan transfer kekayaan ke pemerintah ataupun pada dirinya sendiri (Watt \& Zimmerman, 1986:226; Miller, 1994:7).

\section{Peny usunan Standar Akuntansi : Tinjauan Lintas Negara}

Tinjauan lintas negara ini dimaksudkan untuk mendeskripsikan perbedaan lokasi (tempat) akan menjadikan penyusunan standar ak untansi juga mungkin berbeda, misalnya disebabkan oleh culture influence. Sudarwan (1995) mengungkapkan beberapa studi yang 
membahas mengenai proses standar yang dipengaruhi budaya yaitu tahun 1986 oleh Harrison dan MacKinnon, tahun 1989 oleh Belkaoui, dan tahun 1989 oleh Bloom dan Naciri. Beberapa faktor budaya tersebut, oleh Sudarwan (1995) dirangkum dalam determinsasi bahasa, kekuatan dan kegigihan (budaya) manajer korporasi, ataupun dimensi national culture yang terdiri dari power distance, uncertainty avoidance, conformism, femininity (Donleavy, 1991). Beberapa poin berikut ini akan mendeskripsikan konsekuensi ekonomi dan politik dalam praktek penyusunan standar akuntansi internasional negara terkait karena determinsasi bud aya di atas.

Lobi politik dalam International Acounting Standard Board (IASB) juga dilakukan oleh industri dan pihak yang terkait lainnya baik itu dari USA maupun negara lainnya (Zeff, 2002). Tekanan politik juga terjadi di beberapa negara terkait dengan IASB misalnya Australia, Kanada, Prancis, Jerman, Jepang, New Zeland, UK, dan USA. Zeff memberi contoh saat IASC membatasi penggunaan LIFO melalui Comparability of Financial Statement, IOSCO (International Organization of Securities Commissions) menolak pembatasan penggunaan LIFO, USA dan Kanada juga lebih suka mempertahankan LIFO. Delegasi dari negara seperti Korea, Jepang, Jerman, dan Italia juga menolaknya. Akhirnya diputuskan voting dengan kemenangan mempertahankan LIFO. Beberapa konsekuensi ekonomi yang bisa dianalisis adalah mengenai implikasi LIFO terhadap tujuan pajak pendapatan, atau ketentuan laporan keuangan pajak.

Meskipun begitu Dye dan Sunder (2001) mengungkapkan beberapa argumen mengapa FASB dan IASB tidak boleh bersaing di Amerika. Beberapa alasan mengenai status quo yaitu keandalan FASB yang sudah terjamin, resiko deadlock atau membuka permusuhan antar kepentingan, ataupun biaya aplikasi penyusunan standar. Kaitan dengan 
hal ini, IAS masih tetap diperlukan karena adanya globalisasi bisnis, dan argumen kemiripan standar.

\section{Amerika Serikat, Inggris, Australia, dan Jerman : Negara Ekonomi Pasar Bebas}

Contoh konsekuensi ekonomi dan proses politik di Amerika telah di bahas di depan. Di Inggris telah terjadi proses politk atas penerapan akuntansi pajak tangguhan (SSAP No. 11) dikarenakan adanya inflasi 25\% pada bulan Agustus 1975. Selanjutnya, di bulan Oktober 1978 dewan standar Inggris (ASC) mengganti SSAP No.11 dengan 15 berdasarkan pertimbangan konsituen (terutama karena pertimbangan pertumbuhan dan current sharholders). Proses politik juga terjadi di Australia. Senat melakukan veto satu bagian dari standar akuntansi. Bahkan parlemen Australia juga melakukan penolakan secara kasar terhadap penyusun standar pada Februari 2002 dengan disponsori oleh senat melalui "disallowance motion" atas penggunaan nilai buku atas akuisisi asset daripada nilai wajar. Hal tersebut telah menjadi pertentangan sengit dalam konggres.

Proses lobi kostituen di Jerman juga merupakan hal yang menarik mengingat pihak legislatif bertanggungjawab atas pengembangan regulasi pelaporan keuangan. Di Jerman, aturan akuntansi dibuat dan diusulkan oleh pengacara dan administrator Menteri Kehakiman dan Keuangan (McLeay et.al., 2000). Aturan akuntansi diformulasikan dalam Accounting Directives Law (Bilanzrichtlinien-Gezertz) dengan berbagai pertimbangan kepentingan kostituen. Artinya, aturan akuntansi sudah seperti regulasi pajak saja, sehingga lobi kostituen melewati harus melalui prosedur legislatif. Penelitian McLeay et.al. (2000) menguji partisipasi tiga konstituen yaitu akademisi, auditor, dan industri. Partisipasi cukup tinggi diberikan oleh kalangan industri Jerman pada legislatur meskipun usulan proposal sedikit mirip dengan kalangan akademis. Meskipun pihak industri adalah 
pemakai utama, kalangan akademisi cukup menentukan dalam proses lobi dewan legislatif terbukti dengan seringnya memberikan saran-saran maupun pendapat atas berbagai terbitan standar ataupun exprosure draft-nya.

\section{The Development Accounting Standard in China}

Meskipun negara sosialis, RRC melalui revolusi 1976 telah bergerak menuju "socialist market economic systems" atau ekonomi terencana dengan adaptasi pasar. Implikasinya, berbagai privatisasi telah dilakukan terutama setelah Central Committee of China's Communist mengajukan konsep percepatan ekonomi melalui transisi ekonomi pasar. Pergeseran menuju swastanisasi kepemilikan memerlukan revisi sistem pelaporan keuangan, revisi standar akuntansi dan disclousure merupakan kunci keberhasilan reformasi ekonomi (Winkle et.al., 1994).

Perkembangan standar akuntansi di RRC dikomandoi oleh Menteri Keuangan dimulai tahun 1992, dan efektif 1 Juli 1993. Dengan konsultan Deloitte Touche Thomatsu (DTT), diterbitkanlah "Accounting Standards for Business Enterprises". Ciri khas standar tetap pada tingkat intervensi pemerintah yang tinggi, menekankan pada dasar historical costing, dan teori ekuitas yang dipakai tetap pada dominasi kepemilikan negara. Selain itu, harus ada kejelasan distribusi profit pada pemerintah atas kepemilikan negara dan publik sebagai cirri melekatnya prinsip negara sosialis. Permasalahan mulai timbul saat RRC mulai menggunakan investasi luar negeri untuk mengembangkan sektor riilnya. Hal ini memaksa negara tersebut untuk memulai melakukan internasionalisasi standar. Padahal mereka harus menggunakan dasar penyajian laporan keuangan yang akomodatif terhadap tiga pihak pengguna yaitu investor, kreditur, dan pemerintah. Diungkapkan oleh Tang (2000) bahwa harus ada revisi standar dasar (basic standard) untuk merespon hal itu, tapi 
hal itu belum diakomodasi oleh Menteri Keuangan. Belakangan ternyata standar yang diterbitkan telah berfokus utama (sudah akomodatif) pada investor luar negeri sebagai alat untuk mempermudah masuknya permodalan luar negeri.

Perjalanan panjang akuntansi di RRC merupakan bentuk dari implikasi ideologi yang dianut suatu negara. Meskipun demikian, faktor lain seperti kond isi masyarakat yang apatis, akuntan yang belum terampil, CPA yang tidak independen, atau budaya riset yang masih kurang, menjadikan perkembangan standar akuntansi di RRC tidak secepat negaranegara barat.

\section{KESIMPULAN}

Konsekuensi ekonomi cukup meyakinkan untuk menjadi dasar dalam proses penyusunan standar akuntansi. Pihak yang terkait, atau terkena dampak standar akuntansi (berdasarkan efek transfer kekayaan), akan melakukan proses politik guna memperoleh solusi yang menguntungkan dirinya atau grupnya. Bahkan proses politik sendiri sudah benar-benar menjadi suatu "permainan politik praktis" ketika pemerintah atau politisi membuat/mengintervensi regulasi akuntansi untuk mengamankan kepentingan mereka, ataupun memaksimalisasi kendali yang menguntungkan (memberikan transfer kekayaantransfer of wealth) bagi pemerintah atau politisi secara individual.

Proses politik banyak terjadi di negara pasar bebas, apalagi untuk negara yang menganut ekonomi sosialis. Studi di Cina menunjukkan pengaruh kuat intervensi pemerintah dalam proses penyusunan standar akuntansi, terutama dalam menjaga ideologi sosialis tetap terjaga dengan mengedepankan 3 (tiga) pemakai laporan keuangan yaitu pemerintah, investor, dan kreditur. Standar akuntansi di RRC merupakan 
dampak/konsekuensi dari peralihan sistem ekonomi menuju "socialist market " dan masuknya investasi luar negeri yang cukup besar.

Tulisan ini diharapkan mampu memberikan gambaran bahwa standar akuntansi sebenarnya merupakan adopsi berbagai kepentingan konstituen, dan bukanlah suatu proses yang serba jadi. Karena luasnya tulisan ini, pemaparan beberapa hal cenderung tidak mendalam, sehingga masih membutuhkan penyempurnaan dari berbagai riset empiris atau paper normatif yang membahas satu sub-pokok bahasan yang lebih mendetail. 


\section{DAFTAR PUSTAKA}

Belkaoui, Ahmed R., 2000, Accounting Theory (terjemahan), Thompson Learning Asia

Beresford, Dennis R., L. Todd Johnson, 1995, Interactions between the FASB and the Academic Community, Accounting Horizon Vol. 9 No. 4 pp. 108-117

Bowen, Robert M., Larry Du. Chame, D.Shores, 1995, Stakeholders Implicit Claims on Accounting Method Choice, Journal of Accounting and Economic 20

Chow, Chee W., 1983, The Impact of Accounting Regulation on Bondholders and Shareholders Wealth: The Case of the Security Act, The Accounting Review, Vol. LVIII No. 3

Donleavy, G.D., 1991, Asia Pacific Accounting Harmonization in the 1990s, TKPA.

Dye, Ronald A., Syam Sunder, 2001, Why not Allow FASB and IASB Standard to Compete in US, Accounting Horizon Vol. 15 No. 3, pp. 257-271

Khurana, Inder K., Martha L. Loudder, 1994, The Economic Consequences of SFAS 106 in Rate-Regulated Enterprises, Accounting Review, Vol. 69 No. 2

Luehlfing, Michael S., 1995, The Politics of Self Imposed Regulations-Has A New Day Dawned?, Accounting Horizon Vol. 9 No. 3

Mathews, M.R. dan M.H.B. Perrera, 1993, Accounting Theory and Development, Second Edition, Thomas Nelson Australia

Mc Leay, Stuart, Dieter Ordelhide, Steven Young, 2000, Constituent Lobbying and Its Impact on the Development of Financial Reporting Regulations: Evidence from Germany, Accounting, Organizations and Society 25 pp. $79-98$

Miller, Peter, 1994, Accounting as Social and Institutional Practice: An Introuction, Accounting as Social and Institutional Practice (edited by Anthony G. Hopwood dan Peter Miller), Cambridge University, Melbourne.

Roslender, Robin, 1992, Sociological Prespective on Modern Accountancy, Routledge, London. 
Scott, William R., 1997, Financial Accounting Theory, Prentice-Hall, New Jersey.

Scroeder, Richard G., dan Myrtle Clark, 1995, Accounting Theory: Text and Readings, Fifth Edition, John Wiley \& Sons, Inc.

Sudarwan, 1995, The Dynamic Relationship between Culture and Accounting: An Empirical Examination of the Indonesian Setting, Accounting Development in Indonesia, Publication No. 22.

Tang, Yunwey, 2000, Bumpy Road Leading to Internationalization: A Review of Accounting Development in China, Accounting Horizons, Vol. 14 No. 1

Watt, Ross L., 1977, Corporate Financial Statements, A Product of the Market and Political Process, Australian Journal of Management 2 (April 1977)

Watts, R. L., J.L. Zimmerman, 1986, Positive Accounting Theory, Prentice-Hall

Wibisana, M. Jusuf, 1992, Kerangka Konseptual dan Penyusunan Standar Akuntansi, Accounting Development in Indonesia, Publication No. 9.

Winkle, Gary M., H. Fenwick Huss, Chen Xi-Zhu, 1994, Accounting Standard in the People's Republic ofChina, Accounting Horizon, Vol. 8 No.3

Zeff, S, A., 2002, "Political" Lobbying on Proposed Standars: A Challenge to the IASB, Accounting Horizon Vol. 16 No.1.

Zeff, S.A., 1978, The Rise of Economic Consequences, Journal of Accountancy-December 1978.

* Helmy Adam, SE., MSA., Ak., Dosen Fakultas Ekonomi Universitas Brawijaya Malang 